\title{
Percepção de escolares e enfermeiros quanto às práticas educativas do programa saúde na escola
}

\author{
Students and nurses perception regarding the educational practices of the health at school \\ program
}

Percepción de estudiantes y enfermeras sobre las prácticas educativas del programa de salud en la escuela

Katrine Nascimento de Carvalho ${ }^{(\mathbb{D})}$, Luciane Zanin $^{1}{ }^{(\mathbb{D}}$, Flavia Martão Flório ${ }^{1}$ * $^{(\mathbb{D}}$

${ }^{1}$ Faculdade São Leopoldo Mandic - Campinas, SP, Brasil.

\section{Resumo}

Objetivo: Identificar as dificuldades do enfermeiro nas ações desenvolvidas no PSE e avaliar a percepção dos alunos sobre o programa. Métodos: 6 enfermeiros e 358 alunos de escolas públicas vinculadas ao PSE do município de Parnaíba-Piauí-Brasil responderam a um questionário pré-testado, adequado ao público alvo: escolares ou profissionais. Resultados: Alunos reconheceram a atuação do enfermeiro no cenário escolar, mas a maioria relatou que não houve avaliação dos problemas de saúde, que não teve pressão arterial verificada, que não foram orientados sobre hábitos nutricionais e que nunca receberam orientações sobre vacinação. A ação com maior coerência nas respostas entre os participantes foi aferição do peso e altura $(65,6 \%)$ e a de menor foi a avaliação da visão (15,4\%). Conclusão: Os enfermeiros destacam que o excesso de atribuições na UBS, a ausência de envolvimento das escolas e a falta de articulação intersetorial são os principais problemas para a boa execução do PSE.

Palavras-chave: Serviços de Saúde Escolar; Promoção da Saúde; Enfermeiros; Relações Enfermeiro-Paciente; Conhecimentos em Saúde; Atitudes e Prática em Saúde; Atenção à Saúde.

Como citar: Carvalho KN, Zanin L, Flório FM.Percepção de escolares e enfermeiros quanto às práticas educativas do programa saúde na escola. Rev Bras Med Fam Comunidade. 2020;15(42):2325. https://doi.org/10.5712/rbmfc15(42)2325

\author{
Autor correspondente: \\ Flavia Martão Flório. \\ E-mail: flaviaflorio@yahoo.com \\ Fonte de financiamento: \\ declaram não haver. \\ Parecer CEP: \\ CAAE 67765917.2.0000.5374. \\ Procedência: \\ não encomendado. \\ Recebido em: 20/12/2019. \\ Aprovado em: 09/10/2020.
}




\begin{abstract}
Objective: To identify the difficulties of the nurse performance in the actions carried out in the PSE, and to evaluate the student's perception about the program through validated questionnaires containing open and closed questions. Methods: 6 nurses and 358 students from public schools located in the city of Parnaíba-Piauí-Brazil answered a pre-tested questionnaire appropriate for the target audience: students or professionals. Results: Students acknowledged the nurse's performance in the school setting, but the majority reported that there was no assessment of health problems, no blood pressure checked, no orientation on nutritional habits and no guidance on vaccination. The action with the most coherence in the responses among the participants was the measurement of weight and height (65.6\%) and the lowest was the assessment of vision (15.4\%). Conclusion: The nurses highlight that the excess of assignments in the UBS, the lack of involvement of schools and the lack of intersectoral articulation are the main problems for the good execution of the PSE.
\end{abstract}

Keywords: School Health Services; Health Promotion; Nurses; Nurse-Patient Relations; Health Knowledge; Attitudes, Practice, Health Care; Public Health.

\title{
Resumen
}

Objetivo: Identificar las dificultades de los enfermeros en las acciones desarrolladas en el PSE y evaluar la percepción de los estudiantes sobre el programa. Métodos: 6 enfermeros y 358 estudiantes de escuelas públicas de la ciudad de Parnaíba-Piaúi-Brasil respondieron un cuestionario previamente aprobado. Resultados: Los estudiantes reconocieron el desempeño de lo enfermero en el entorno escolar, pero la mayoría informó que no hubo una evaluación de los problemas de salud, no se verificó la presión arterial, no hubo orientación sobre los hábitos nutricionales y ningún consejo sobre la vacunación. La acción con la mayor coherencia en las respuestas entre los participantes fue la medición del peso y la altura $(65,6 \%)$ y la más baja fue la evaluación de la visión $(15,4 \%)$. Conclusión: Las enfermeras destacan que el exceso de atribuciones en la UBS, la falta de participación de las escuelas y la falta de articulación intersectorial son los principales problemas para la buena ejecución del PSE

Palabras clave: Servicios de Salud Escolar; Promoción de la Salud; Enfermeros; Relaciones Enfermero-Paciente; Conocimientos en Salud; Actitudes y Práctica en Salud; Atención a la Salud.

\section{INTRODUÇÃO}

A promoção da saúde deve ocorrer de maneira eficaz e não impositiva, priorizando-se práticas que respeitem as diferenças dos envolvidos, fazendo da educação em saúde uma verdadeira ferramenta de empoderamento do indivíduo. ${ }^{1}$ Para crianças e adolescentes, a escola é o melhor local para a prática da educação em saúde, porque este espaço é adequado para promover ações educativas com o envolvimento de diferentes grupos sociais, onde se destaca a coparticipação dos escolares, dos pais, educadores e profissionais da saúde, ${ }^{2}$ que juntos têm uma maior chance de encontrar soluções para os mais diversos problemas. Portanto, os processos de educação em saúde na escola ajudam crianças e adolescentes a adquirirem um comportamento social voltado aos melhores métodos de prevenção aos problemas de saúde, como também, esclarecer a população no sentido de adotar um estilo de vida saudável. ${ }^{3}$ Neste contexto, o enfermeiro deve contribuir exercendo, além de suas funções profissionais, o papel de educador, trabalhando com a realização de atividades que estimulem a saúde e a qualidade de vida por meio da educação, atuando de maneira efetiva e, desta forma, contribuindo para o desenvolvimento do escolar e da sua comunidade. ${ }^{4}$

O programa saúde na escola (PSE), foi instituído pelo Decreto Presidencial n 6.286/2007 e caracteriza-se por ser uma política intersetorial que atende aos princípios e diretrizes do Sistema Único de Saúde (SUS). ${ }^{5}$ O programa se propõe a ser um modelo de atenção à saúde com finalidade de contribuir para a formação integral dos escolares da rede básica por meio de ações de prevenção, promoção e atenção à saúde. ${ }^{6}$ As ações são planejadas pelas secretarias de saúde e de educação, como também, podem ser planejadas por demanda solicitada pelos diretores das escolas. ${ }^{7}$

Nesta temática, os estudos têm procurado analisar os efeitos das ações do PSE nos escolares realizadas por equipe específica ou não do PSE ou mesmo considerando a participação da equipe de 
profissionais das escolas. ${ }^{7-10}$ A participação do enfermeiro no PSE vem sendo avaliada, considerando-se a evolução de sua atuação como responsável social, ou seja, como o profissional que tem o compromisso de contribuir para que os membros da sociedade tenham acesso às ferramentas que promovam saúde, seja na comunidade, seja na escola. ${ }^{8-10}$ No PSE o enfermeiro atua como um facilitador, um incentivador para o desenvolvimento de habilidades do autocuidado na promoção em saúde, que permite a independência do indivíduo no âmbito do cuidar, ${ }^{10}$ sendo verificado que o programa propiciou repercussões positivas, por fortalecer o enfrentamento das vulnerabilidades em saúde, que podem comprometer o pleno desenvolvimento escolar, além de promover a comunicação, encaminhamento e resolutividade entre unidades de saúde e escolas, por meio de ações de atenção e cuidado sobre as condições de saúde dos escolares. ${ }^{11}$

Avaliações sobre o PSE são importantes e permitem estimar o rumo das estratégias adotadas, face à importância do programa na adoção de estilos de vida saudáveis com repercussões positivas para toda a vida. ${ }^{12}$ Embora o PSE esteja em atividade no município desde 2009, não há na região estudos anteriores considerando o concomitante olhar do enfermeiro e do estudante sobre esta temática.

Desta forma, este trabalho teve como objetivo identificar as dificuldades do enfermeiro nas ações desenvolvidas no PSE, identificar as atividades vivenciadas por este profissional de saúde e avaliar a percepção dos alunos sobre o programa e as ações desenvolvidas.

\section{MÉTODOS}

\section{Tipo de estudo}

Estudo observacional de natureza quanti-qualitativa do tipo analítico transversal, realizado no período de abril a junho de 2017.

\section{Local estudo}

A pesquisa foi desenvolvida no segundo município mais populoso do estado do Piauí, denominado Parnaíba, no qual o PSE tem sido desenvolvido desde 2009. Em 2017, o município contava com 41 unidades básicas de saúde vinculadas à estratégia saúde da família, cada uma das quais com uma equipe de saúde. A rede municipal de ensino era composta por 95 escolas de ensino básico. Como critério de inclusão da escola no estudo primeiramente considerou-se as escolas que possuíam o segundo ciclo do ensino fundamental ( $6^{\circ}$ ao $9^{\circ}$ ano), sendo elegíveis 9 escolas. Destas foram incluídas as 6 escolas cujo enfermeiro da equipe atuava há pelo menos um ano no desenvolvimento do programa PSE.

\section{Participantes da pesquisa}

Participaram da pesquisa os 6 enfermeiros que atuavam de forma individual em cada uma das escolas selecionadas e os escolares matriculados no $6^{\circ}$ ano do ensino fundamental. Todas as escolas incluídas no estudo eram localizadas na zona urbana e com funcionamento no período diurno.

Para o cálculo do tamanho amostral de escolares participantes considerou-se os seguintes parâmetros: proporção esperada de $50 \%$, grau de confiança de $95 \%$, margem de erro de $5 \%$ e ajuste para população finita de 534 escolares matriculados no $6^{\circ}$ ano do ensino fundamental, resultando em uma amostra mínima 
de 223 indivíduos. A esse valor foi somado 10\% de taxa de não resposta, correspondendo uma amostra mínima de 245 escolares. Todos os alunos foram convidados a participar, dentre estes 358 aceitaram o convite.

\section{Coleta dos dados}

A técnica de coleta de dados foi baseada na aplicação de questionários para os escolares e para os enfermeiros que teve como referência um instrumento já validado ${ }^{10}$ adequado aos objetivos do presente estudo, com a inclusão de pergunta sobre as dificuldades dos profissionais na execução do PSE, sobre as atividades executadas pelos profissionais, de acordo com os componentes do PSE. Ressalta-se que os questionários versavam sobre os mesmos temas e diferiam apenas em relação à adequação de termos ao grupo de interesse.

Os questionários foram compostos por 3 blocos:

Bloco 1 - perfil demográfico: gênero, idade, raça;

Bloco 2 - conhecimentos gerais e práticas em saúde: contendo questões abertas, fechadas e mistas relacionadas aos conhecimentos sobre o PSE;

Bloco 3 - avaliação das atividades do PSE, contendo um quadro em que as 26 ações de saúde, elencadas segundo o caderno do gestor do PSE, ${ }^{13}$ as quais foram pontuadas de forma que o respondente marcasse "sim" para as ações realizadas/vivenciadas na escola e "não" para as ações não realizadas/não vivenciadas.

\section{Análise dos dados}

Para a análise das respostas das questões abertas interpretou-se as falas dos enfermeiros realizando, inicialmente, a leitura atenta de cada depoimento, separando-os em categorias para cada resposta. Foi utilizada a abordagem qualitativa por meio da análise de conteúdo, segundo proposta de Bardin (1977). ${ }^{14}$ Para preservar a identidade dos participantes, os enfermeiros foram simbolizados com "E" de enfermeiro, organizados numa sequência de 1 a 6 . Cada resposta foi analisada e interpretada sob o aspecto de uma problematização crítico-reflexiva, de acordo com as questões suscitadas.

Os demais dados foram analisados por meio de estatística descritiva e tabelas de distribuição de frequências absolutas e relativas. As respostas dos escolares e enfermeiros, sobre as atividades realizadas no PSE, foram comparadas considerando-se a frequência de respostas concordantes: acima de $80 \%$ (ótima), entre 50\% e 79\% (satisfatória), entre 49\% e 25\% (insatisfatória) e menor de 25\% (inexistente). As análises foram realizadas no programa $\mathrm{R}$ Core Team. ${ }^{15}$

\section{Procedimentos éticos}

O estudo foi aprovado pelo Comitê de Ética em Pesquisa da instituição sob o CAAE $n^{\circ}$ 67765917.2.0000.5374, tendo sido conduzido de acordo com as normas e diretrizes de pesquisa com seres humanos, conforme a Resolução n 466/12 do Conselho Nacional de Saúde.

\section{RESULTADOS}

\section{Relacionados aos enfermeiros}

Os 6 enfermeiros participantes deste estudo eram do sexo feminino (100\%), com idade média de $44,3( \pm 3,7)$ anos e com tempo médio de atuação de 10,2 $( \pm 5,3)$ anos. Destacaram como dificuldades e 
problemas de saúde apresentados pelos escolares o desenvolvimento emocional e comportamental da criança: "dificuldade de adaptação, desempenho comportamental alterado" e "falta de concentração do alunato, consumo e venda de drogas dentro da escola". Destaca-se, ainda, em algumas falas outros problemas de saúde: "verminose, falta de higiene, alimentação inadequada" e "verminose, tuberculose, dengue, hanseníase, gravidez na adolescência e uso de drogas".

\section{Categoria 1: o PSE e a intersetorialidade}

Os enfermeiros conceituaram o PSE de uma forma geral como "política intersetorial entre educação e saúde", como demonstram as seguintes respostas:

"Articulação entre saúde e educação, visando melhorar a qualidade de vida do escolar." (E2)

"Integração e articulação permanente da educação e saúde, proporcionando qualidade de vida de alunos, com prevenção de doenças e agravos em saúde." (E4)

\section{Categoria 2: importância do PSE}

Em relação à sua importância, destacou-se o desenvolvimento de hábitos saudáveis, a promoção da saúde e qualidade de vida, a prevenção de agravos, além da oportunidade do diagnóstico precoce:

"Para o desenvolvimento de hábitos saudáveis, manutenção da saúde e contribuir para a qualidade de vida." (E1)

"Avalia escolares que não consegue consulta na unidade, para triar doenças em fase inicial." (E2)

"Promove a educação escolar para promoção e prevenção de agravos." (E6)

\section{Categoria 3: dificuldades apontadas pelo enfermeiro na execução do PSE}

Os profissionais destacaram dificuldades relacionadas à infraestrutura disponível, além de outras relacionadas aos atores envolvidos:

"Falta de compromisso de professores e direção escolar, falta de apoio da secretaria de saúde." (E2)

"Não adesão de pais e responsáveis, não envolvimento de docentes e diretores, muitas atividades na ESF." (E3)

"Falta cartão do SUS para produção exigida, falta de materiais e recursos para as atividades, falta de coordenador do PSE para nos orientar. Tudo solto." (E6)

\section{Categoria 4: benefícios para saúde do escolar}

Dentre os benefícios ao escolar, foi identificado nas falas a formação do cidadão, o enfrentamento das vulnerabilidades além da possibilidade de transformação social:

"Formação cidadão, promoção de saúde, qualidade de vida na sociedade." (E1)

"Prevenir vulnerabilidade, propiciar diálogos com temáticas recorrentes, possibilitar transformação social." (E4)

Na Tabela 1 nota-se que os enfermeiros relataram realizar nas escolas atividades de educação em saúde, citando a participação dos dentistas, seguidos de médicos, nutricionistas e psicólogos; relataram também que planejam as atividades junto com a equipe.

\section{Relacionados aos escolares}

A amostra de escolares era majoritariamente composta por meninos $(52,2 \%)$, com idade média de $12,5( \pm 1,3)$ anos, de cor de pele não branca $(77,9 \%)$, cujas famílias constituíam-se por $5,2( \pm 2,3)$ membros. 
Quando perguntados sobra a avaliação das ações em saúde desenvolvidas na escola, 62,6\% classificaramnas como ótima e boa, $21,8 \%$ como regulares e 10,1\% como ruins. Na Tabela 2 nota-se que a maioria dos escolares reconhece a importância de receber orientações de saúde dentro escola, como também aponta existir ações de promoção da saúde em suas escolas. Por outro lado, a grande maioria não reconhece a atuação dos diferentes profissionais de saúde em suas escolas, dado preocupante, porque revela que nem todos os profissionais de saúde que constam no programa participam da promoção à saúde nas escolas deste município ou são reconhecidos como participantes. Este dado reflete a resposta de 27,9\% dos escolares que não consideram existir um trabalho voltado para a promoção da saúde nas escolas, seja por falta de esclarecimento das atividades desenvolvidas pelo PSE na escola, seja porque o escolar não foi capaz de identificar que as atividades promovidas pelo PSE são para promoção de sua saúde.

Relatos quanto as ações desenvolvidas na escola - enfermeiros e escolares

Quando os enfermeiros foram indagados sobre as atividades realizadas para a promoção da saúde nas escolas, todos responderam as ações descritas na Tabela $3 \mathrm{e}$, dentre elas nota-se que apenas a verificação de peso e altura foi percebida pela maioria dos escolares, nas escolas A, B e E. Para as crianças da escola $F$, a percepção sobre as ações realizadas foi nula ou insatisfatória

A Tabela 4 apresenta a resposta dos enfermeiros de cada uma das escolas, sobre a realização das ações listadas ("sim" ou “não") e a proporção (\%) de respostas afirmativas das crianças quanto a realização

Tabela 1. Análise descritiva do questionário sobre perguntas gerais para os enfermeiros (Parnaíba/PI, abril de 2017).

\begin{tabular}{|c|c|c|c|c|}
\hline \multirow[b]{2}{*}{ Pergunta } & \multicolumn{2}{|c|}{ Não } & \multicolumn{2}{|c|}{ Sim } \\
\hline & $\mathbf{n}$ & $\%$ & $\mathbf{n}$ & $\%$ \\
\hline Você tem realizado atividades de educação em saúde na escola? & 0 & $0,0 \%$ & 6 & $100,0 \%$ \\
\hline Médicos & 2 & $33,3 \%$ & 4 & $66,7 \%$ \\
\hline Dentistas & 0 & $0,0 \%$ & 6 & $100,0 \%$ \\
\hline Nutricionistas & 5 & $83,3 \%$ & 1 & $16,7 \%$ \\
\hline Educadores físicos & 6 & $100 \%$ & 0 & $0 \%$ \\
\hline Você planeja, junto com a equipe, as atividades do PSE? & 0 & $0,0 \%$ & 6 & $100,0 \%$ \\
\hline
\end{tabular}

Tabela 2. Análise descritiva do questionário sobre perguntas gerais para os escolares (Parnaíba/PI, abril de 2017).

\begin{tabular}{lcccc}
\hline & Não & Sim & & \\
Pergunta & $\mathbf{n}$ & $\%$ & $\mathbf{n}$ & $\%$ \\
\hline $\begin{array}{l}\text { Você considera que há um trabalho voltado para a promoção } \\
\text { da sua saúde na escola? }\end{array}$ & 100 & $27,9 \%$ & 258 & $72,1 \%$ \\
É importante receber orientações de saúde na escola? & 16 & $4,5 \%$ & 342 & $95,5 \%$ \\
Profissionais que realizam orientações de saúde na sua & & & & \\
escola: & & & & $17,9 \%$ \\
Médicos & 294 & $82,1 \%$ & 64 & $30,2 \%$ \\
Enfermeiros & 250 & $69,8 \%$ & 108 & $27,1 \%$ \\
Dentistas & 261 & $72,9 \%$ & 97 & $17,6 \%$ \\
Psicólogos & 295 & $82,4 \%$ & 63 & $17,3 \%$ \\
Nutricionistas & 296 & $82,7 \%$ & 62 & $21,5 \%$ \\
Educadores físicos & 281 & $78,5 \%$ & 77 & \\
\hline
\end{tabular}


de cada uma das ações. As cores representam a concordância entre as respostas dos enfermeiros e das crianças, variando de acima de $80 \%$ (azul) até menos de 25\% (vermelho). Nota-se que nenhum dos enfermeiros relatou realizar avaliação auditiva e orientação sobre problemas auditivos, sendo que estas foram as únicas ações em que houve concordância entre as respostas da maioria dos escolares e dos profissionais, em todas as escolas.

\section{DISCUSSÃO}

Foi possível observar que embora os enfermeiros tenham relatado a realização de ações em saúde nas escolas, a maioria destas não foram percebidas pelos escolares. Além disso, poucas foram as respostas dos escolares que convergiram às dos enfermeiros, tornando clara a divergência entre os grupos estudados quanto à percepção das ações realizadas no PSE. Este achado deve ser analisado no contexto de que independentemente do número de escolares nas turmas, apenas um único enfermeiro por ESF foi designado para a prática do PSE nas escolas, o que torna muito difícil contemplar todas as atividades do PSE, o que se reflete na fala dos alunos, que não reconhecem o trabalho voltado para a promoção de saúde nas escolas.

Aexclusividade do enfermeiro no desenvolvimento das ações de promoção da saúde não está explicitada no $\mathrm{PSE}^{6,16}$ e todos os profissionais que atuam na equipe devem cumprir esse papel como equipe multidisciplinar ${ }^{16,17}$ e intersetorial. ${ }^{18}$ Este trabalho revelou a presença de outros profissionais de saúde atuando na escola, sendo o dentista a segunda categoria profissional mais percebida pelos escolares depois dos enfermeiros e a única categoria citada por todos os enfermeiros dentre os profissionais com ações de saúde na escola. Isso pode estar relacionado ao histórico de atuação do dentista na escola desde a década de 1950, quando, por meio do sistema incremental, este profissional foi alocado exclusivamente nas escolas, executando uma programação de caráter preventivo-curativo hegemônica por mais de quatro décadas no Brasil. ${ }^{19}$ Esta herança, aliada a cada vez mais proeminente atuação das equipes de saúde bucal na estratégia saúde da família ${ }^{20}$ podem justificar a

Tabela 3. Porcentagem de respostas afirmativas dos escolares para as ações em que $100 \%$ dos enfermeiros apontou como realizadas nas escolas (Parnaíba/PI, abril de 2017).

\begin{tabular}{|c|c|c|c|c|c|c|c|}
\hline \multirow[t]{2}{*}{ Ação } & \multicolumn{7}{|c|}{ Resposta afirmativa sobre realização da atividade (\% escolares) } \\
\hline & Escola A & Escola B & Escola C & Escola D & Escola E & Escola F & Total \\
\hline Entrega a caderneta de saúde & $16,7 \%$ & $39,3 \%$ & $47,4 \%$ & $32,4 \%$ & $18,2 \%$ & $36,2 \%$ & $29,3 \%$ \\
\hline Orientação sobre vacinação & $33,3 \%$ & $69,6 \%$ & $63,2 \%$ & $52,7 \%$ & $30,9 \%$ & $34,8 \%$ & $44,1 \%$ \\
\hline Aplicação de vacina & $23,3 \%$ & $53,6 \%$ & $63,2 \%$ & $54,1 \%$ & $32,7 \%$ & $23,2 \%$ & $39,4 \%$ \\
\hline $\begin{array}{l}\text { Avaliação de manchas na pele e } \\
\text { outros problemas de saúde }\end{array}$ & $16,7 \%$ & $26,8 \%$ & $21,1 \%$ & $47,3 \%$ & $11,8 \%$ & $21,7 \%$ & $24,3 \%$ \\
\hline Orientação sobre hábitos nutricionais & $40,0 \%$ & $25,0 \%$ & $21,1 \%$ & $20,3 \%$ & $33,6 \%$ & $17,4 \%$ & $26,3 \%$ \\
\hline Avaliação de saúde bucal & $60,0 \%$ & $62,5 \%$ & $52,6 \%$ & $37,8 \%$ & $25,5 \%$ & $18,8 \%$ & $36,9 \%$ \\
\hline $\begin{array}{l}\text { Atividades de escovação ou } \\
\text { aplicação de flúor }\end{array}$ & $73,3 \%$ & $57,1 \%$ & $68,4 \%$ & $37,8 \%$ & $28,2 \%$ & $18,8 \%$ & $38,8 \%$ \\
\hline $\begin{array}{l}\text { Orientação sobre os problemas de } \\
\text { saúde bucal }\end{array}$ & $73,3 \%$ & $44,6 \%$ & $57,9 \%$ & $43,2 \%$ & $22,7 \%$ & $13,0 \%$ & $34,6 \%$ \\
\hline $\begin{array}{l}\text { Encaminhamento para a UBS } \\
\text { quando há um problema de saúde }\end{array}$ & $23,3 \%$ & $60,7 \%$ & $63,2 \%$ & $36,5 \%$ & $22,7 \%$ & $17,4 \%$ & $32,7 \%$ \\
\hline Verificação de peso e altura & $93,3 \%$ & $91,1 \%$ & $57,9 \%$ & $48,6 \%$ & $81,8 \%$ & $27,5 \%$ & $65,6 \%$ \\
\hline
\end{tabular}

Legenda: Concordância entre as respostas: maior $80 \%$ - ótima; $79 \%$ a $50 \%$ - satisfatória; 49 a $25 \%$ - insatisfatória; menor 25\% - inexistente. 
Tabela 4. Porcentagem de respostas afirmativas pelos escolares e enfermeiros quanto as atividades de saúde realizadas nas escolas (Parnaíba/PI, abril de 2017).

\begin{tabular}{|c|c|c|c|c|c|c|c|}
\hline \multirow{3}{*}{ Ação } & \multirow{2}{*}{\multicolumn{7}{|c|}{ Resposta afirmativa sobre realização da atividade (\% escolares) }} \\
\hline & & & & & n" ou "Nãc & & \\
\hline & Escola A & Escola B & Escola C & Escola D & Escola E & Escola F & Total \\
\hline Anotam dados na caderneta de saúde & $\begin{array}{l}16,7 \% \\
\text { Sim }\end{array}$ & $\begin{array}{l}44,6 \% \\
\text { Sim }\end{array}$ & $\begin{array}{l}36,8 \% \\
\text { Sim }\end{array}$ & $\begin{array}{l}27,0 \% \\
\text { Sim }\end{array}$ & $\begin{array}{l}29,1 \% \\
\text { Sim }\end{array}$ & $\begin{array}{l}27,5 \% \\
\text { Não }\end{array}$ & $\begin{array}{l}30,2 \% \\
83,3 \%\end{array}$ \\
\hline Realização de avaliação oftalmológica & $\begin{array}{l}20,0 \% \\
\operatorname{Sim}\end{array}$ & $\begin{array}{l}14,3 \% \\
\text { Sim }\end{array}$ & $\begin{array}{l}21,1 \% \\
\operatorname{Sim}\end{array}$ & $\begin{array}{l}24,3 \% \\
\text { Sim }\end{array}$ & $\begin{array}{l}9,1 \% \\
\text { Sim }\end{array}$ & $\begin{array}{l}13,0 \% \\
\text { Não }\end{array}$ & $\begin{array}{l}15,4 \% \\
83,3 \%\end{array}$ \\
\hline Investigação sobre hábitos nutricionais & $\begin{array}{l}36,7 \% \\
\text { Sim }\end{array}$ & $\begin{array}{l}14,3 \% \\
\operatorname{Sim}\end{array}$ & $\begin{array}{l}15,8 \% \\
\operatorname{Sim}\end{array}$ & $\begin{array}{l}9,5 \% \\
\text { Sim }\end{array}$ & $\begin{array}{l}27,3 \% \\
\text { Não }\end{array}$ & $\begin{array}{l}17,4 \% \\
\text { Não }\end{array}$ & $\begin{array}{l}19,8 \% \\
83,3 \%\end{array}$ \\
\hline $\begin{array}{l}\text { Entrega de escova e pasta de dente } \\
\text { para cuidar da saúde dos dentes }\end{array}$ & $\begin{array}{l}36,7 \% \\
\text { Sim }\end{array}$ & $\begin{array}{l}48,2 \% \\
\text { Sim }\end{array}$ & $\begin{array}{l}68,4 \% \\
\text { Sim }\end{array}$ & $\begin{array}{l}37,8 \% \\
\text { Sim }\end{array}$ & $\begin{array}{l}24,5 \% \\
\text { Não }\end{array}$ & $\begin{array}{l}20,3 \% \\
\text { Sim }\end{array}$ & $\begin{array}{l}33,5 \% \\
83,3 \%\end{array}$ \\
\hline Orientação sobre problemas visuais & $\begin{array}{l}16,7 \% \\
\operatorname{Sim}\end{array}$ & $\begin{array}{l}17,9 \% \\
\operatorname{Sim}\end{array}$ & $\begin{array}{l}15,8 \% \\
\operatorname{Sim}\end{array}$ & $\begin{array}{l}17,6 \% \\
\operatorname{Sim}\end{array}$ & $\begin{array}{l}8,2 \% \\
\text { Não }\end{array}$ & $\begin{array}{c}13,0 \% \\
\operatorname{Sim}\end{array}$ & $\begin{array}{l}13,7 \% \\
83,3 \%\end{array}$ \\
\hline $\begin{array}{l}\text { Promoção de atividades sobre o uso } \\
\text { de crack e outras drogas }\end{array}$ & $\begin{array}{l}30,0 \% \\
\text { Sim }\end{array}$ & $\begin{array}{l}37,5 \% \\
\text { Sim }\end{array}$ & $\begin{array}{l}36,8 \% \\
\text { Sim }\end{array}$ & $\begin{array}{l}47,3 \% \\
\text { Sim }\end{array}$ & $\begin{array}{l}22,7 \% \\
\text { Sim }\end{array}$ & $\begin{array}{l}13,0 \% \\
\text { Não }\end{array}$ & $\begin{array}{l}29,6 \% \\
83,3 \%\end{array}$ \\
\hline $\begin{array}{l}\text { Reuniões na escola com pais e/ou } \\
\text { responsáveis para falar sobre saúde }\end{array}$ & $\begin{array}{l}56,7 \% \\
\text { Sim }\end{array}$ & $\begin{array}{l}53,6 \% \\
\text { Sim }\end{array}$ & $\begin{array}{l}63,2 \% \\
\text { Sim }\end{array}$ & $\begin{array}{l}51,4 \% \\
\text { Sim }\end{array}$ & $\begin{array}{l}34,5 \% \\
\text { Não }\end{array}$ & $\begin{array}{l}23,2 \% \\
\text { Sim }\end{array}$ & $\begin{array}{l}42,2 \% \\
83,3 \%\end{array}$ \\
\hline $\begin{array}{l}\text { Promoção de atividades sobre direitos } \\
\text { de crianças e adolescentes }\end{array}$ & $\begin{array}{l}26,7 \% \\
\operatorname{Sim}\end{array}$ & $\begin{array}{l}44,6 \% \\
\text { Sim }\end{array}$ & $\begin{array}{l}36,8 \% \\
\text { Sim }\end{array}$ & $\begin{array}{l}28,4 \% \\
\text { Sim }\end{array}$ & $\begin{array}{l}20,9 \% \\
\text { Não }\end{array}$ & $\begin{array}{c}13,0 \% \\
\text { Não }\end{array}$ & $\begin{array}{l}26,0 \% \\
66,7 \%\end{array}$ \\
\hline $\begin{array}{l}\text { Investigação de casos de doenças nos } \\
\text { familiares }\end{array}$ & $\begin{array}{l}16,7 \% \\
\operatorname{Sim}\end{array}$ & $\begin{array}{l}16,1 \% \\
\operatorname{Sim}\end{array}$ & $\begin{array}{c}21,1 \% \\
\text { Não }\end{array}$ & $\begin{array}{l}33,8 \% \\
\text { Não }\end{array}$ & $\begin{array}{l}11,8 \% \\
\text { Não }\end{array}$ & $\begin{array}{c}13,0 \% \\
\operatorname{Sim}\end{array}$ & $\begin{array}{l}18,2 \% \\
50,0 \%\end{array}$ \\
\hline $\begin{array}{l}\text { Visitas em casa de familiares com o } \\
\text { objetivo de conhecer a realidade }\end{array}$ & $\begin{array}{c}26,7 \% \\
\text { Não }\end{array}$ & $\begin{array}{l}60,7 \% \\
\text { Não }\end{array}$ & $\begin{array}{c}36,8 \% \\
\text { Não }\end{array}$ & $\begin{array}{l}40,5 \% \\
\text { Sim }\end{array}$ & $\begin{array}{l}24,5 \% \\
\text { Não }\end{array}$ & $\begin{array}{l}11,6 \% \\
\text { Não }\end{array}$ & $\begin{array}{l}31,8 \% \\
16,7 \%\end{array}$ \\
\hline Verificação da pressão arterial & $\begin{array}{l}10,0 \% \\
\operatorname{Sim}\end{array}$ & $\begin{array}{l}17,9 \% \\
\text { Não }\end{array}$ & $\begin{array}{l}15,8 \% \\
\text { Não }\end{array}$ & $\begin{array}{l}12,2 \% \\
\text { Não }\end{array}$ & $\begin{array}{l}8,2 \% \\
\text { Não }\end{array}$ & $\begin{array}{l}7,2 \% \\
\text { Não }\end{array}$ & $\begin{array}{l}10,9 \% \\
16,7 \%\end{array}$ \\
\hline Ausculta respiratória & $\begin{array}{l}10,0 \% \\
\operatorname{Sim}\end{array}$ & $\begin{array}{l}7,1 \% \\
\text { Não }\end{array}$ & $\begin{array}{l}0,0 \% \\
\text { Não }\end{array}$ & $\begin{array}{l}9,5 \% \\
\text { Não }\end{array}$ & $\begin{array}{c}5,5 \% \\
\text { Não }\end{array}$ & $\begin{array}{l}4,3 \% \\
\text { Não }\end{array}$ & $\begin{array}{r}6,4 \% \\
16,7 \%\end{array}$ \\
\hline $\begin{array}{l}\text { Orientação sobre documentos (RG, } \\
\text { CPF, ...) }\end{array}$ & $\begin{array}{l}30,0 \% \\
\text { Sim }\end{array}$ & $\begin{array}{l}41,1 \% \\
\text { Não }\end{array}$ & $\begin{array}{c}52,6 \% \\
\text { Não }\end{array}$ & $\begin{array}{l}25,7 \% \\
\text { Não }\end{array}$ & $\begin{array}{l}25,5 \% \\
\text { Não }\end{array}$ & $\begin{array}{c}11,6 \% \\
\text { Não }\end{array}$ & $\begin{array}{l}27,1 \% \\
16,7 \%\end{array}$ \\
\hline Orientação sobre problemas auditivos & $\begin{array}{l}0,0 \% \\
\text { Não }\end{array}$ & $\begin{array}{l}0,0 \% \\
\text { Não }\end{array}$ & $\begin{array}{l}0,0 \% \\
\text { Não }\end{array}$ & $\begin{array}{c}16,2 \% \\
\text { Não }\end{array}$ & $\begin{array}{l}8,2 \% \\
\text { Não }\end{array}$ & $\begin{array}{l}7,2 \% \\
\text { Não }\end{array}$ & $\begin{array}{l}7,3 \% \\
0,0 \%\end{array}$ \\
\hline Realização de avaliação auditiva & $\begin{array}{l}3,3 \% \\
\text { Não }\end{array}$ & $\begin{array}{l}10,7 \% \\
\text { Não }\end{array}$ & $\begin{array}{l}10,5 \% \\
\text { Não }\end{array}$ & $\begin{array}{l}9,5 \% \\
\text { Não }\end{array}$ & $\begin{array}{l}7,3 \% \\
\text { Não }\end{array}$ & $\begin{array}{l}7,2 \% \\
\text { Não }\end{array}$ & $\begin{array}{l}8,1 \% \\
0,0 \%\end{array}$ \\
\hline
\end{tabular}

Legenda: Concordância entre as respostas: maior $80 \%$

$; 79 \%$ a $50 \%$

49 a $25 \%$-insatisfatória; menor $25 \%$ -

convergência dos relatos dos enfermeiros com os escolares, tanto em relação aos profissionais listados quanto em relação às ações de saúde percebidas na maioria das escolas.

A existência do PSE e a execução de suas atividades voltado a atenção à saúde está associada à participação ativa de diversos interlocutores/sujeitos em práticas cotidianas, dentre eles, os profissionais de saúde, educadores e diretores de escola em realizar construções compartilhadas de saberes e produzir aprendizagens expressivas. Desta forma, as atividades realizadas pelas equipes de saúde da família junto às escolas participantes do PSE, devem ser planejadas de forma conjunta entre os profissionais de saúde, a direção das escolas e os representantes da comunidade, ao longo do ano letivo. Este planejamento em conjunto tem a finalidade de pontuar as melhores datas de atuação do profissional e detectar os principais problemas de saúde dos escolares. À vista disso, é possível ressaltar a importância de uma escola que forma cidadãos questionadores e esclarecidos, com habilidades para agir em defesa de sua saúde e de sua qualidade de vida.

A maioria dos alunos identificou apenas a verificação do peso e da altura como práticas em saúde realizadas em sua escola, o que coaduna com a identificação prévia ${ }^{21}$ de uma relação conflituosa das ações de saúde desenvolvidas na escola, apontando o número insatisfatório de visitas pelos profissionais de saúde, 
resultando em atendimentos isolados que prejudicam a percepção das práticas do PSE, com prejuízos na garantia do pleno cuidado. ${ }^{22}$

A maioria dos escolares julgou importante a presença do enfermeiro como facilitador do processo de ensino-aprendizagem sobre saúde no ambiente escolar, onde se encontram diversos contextos sociais, econômicos e culturais. ${ }^{13}$ Nele pode-se favorecer aos alunos e a seus familiares o desenvolvimento de atitude consciente, ativa e transformadora para a vida do indivíduo na sociedade. ${ }^{9,10}$ Reforça-se neste ponto a responsabilidade do ensino básico em garantir que os alunos sejam capazes de conhecer o próprio corpo e dele cuidar, valorizando e adotando hábitos saudáveis, ${ }^{23}$ sendo de fundamental importância que os profissionais do setor da educação deixem de ter uma participação periférica no planejamento e execução das ações do PSE, o que sem dúvida restringe a sua potencialidade..$^{18,24}$

Para que a atenção à saúde atinja seu objetivo, além do esforço dos profissionais de saúde, é de fundamental importância o interesse e participação dos educadores e diretores da escola em fazer chegar até o escolar as informações mínimas necessárias ao esclarecimento de atividades que garantem a promoção à saúde, assim como, as orientações para cuidados diários que o escolar pode fazer em casa, na escola e em sua vida cotidiana. ${ }^{5}$ As visitas das equipes de saúde da família realizadas periodicamente às escolas participantes do PSE também devem contar com a participação da comunidade, ao longo do ano letivo, esclarecendo-a sobre as condições de saúde destes escolares, de acordo com as necessidades locais de saúde identificadas.

Neste contexto, a baixa frequência da convergência entre as respostas do enfermeiro e dos escolares pode também ser compreendida pela apontada falta de cooperação das escolas e seus atores, fato este também explicitado anteriormente. ${ }^{18,24}$ É de fundamental importância a participação contínua da comunidade escolar de forma que as estratégias sejam esclarecidas e metas definidas para o convívio social saudável. ${ }^{24}$ Apesar de já existir um efetivo trabalho do enfermeiro na escola, faz-se necessário a melhor identificação desse profissional perante as crianças e um cronograma de atividades desenvolvidas pelo PSE com maior frequência no ambiente escolar.

Apenas existiu uma convergência entre escolares e enfermeiros, em relação a não realização de avaliação auditiva. A realização desta ação permitiria a identificação de problema auditivo e consequentes déficits na aquisição do vocabulário e habilidades articulatórias, possibilitando a melhora no desempenho de tarefas escolares que exigem leitura e escrita. ${ }^{25}$

De acordo com as falas dos enfermeiros o trabalho desenvolvido no PSE é importante para a formação da cidadania, para a promoção da qualidade de vida e para o enfrentamento de vulnerabilidades, o que está de acordo a prerrogativa do programa. ${ }^{6}$ Para a sua sustentabilidade é fundamental a superação do modelo biomédico pela aplicação da proposta promotora de saúde, que considera as necessidades específicas dos escolares em condição de maior vulnerabilidade e promove o atendimento de problemas não só ao indivíduo, mas à comunidade escolar. ${ }^{26}$ Neste estudo, foi observado na fala dos enfermeiros um resultado insatisfatório para o encaminhamento dos escolares para UBS quando se identifica algum problema de saúde. Diante desta constatação, se faz necessário o esclarecimento de que o escolar não pode depender da avaliação apenas do enfermeiro e dos momentos em que são realizadas as atividades de promoção à saúde do PSE, pois independente das atividades desenvolvidas pelo programa, a avaliação do estado de sua saúde deve ser realizada em uma unidade básica de saúde, por profissionais das equipes de saúde da família. 
O PSE permite a ampliação intersetorial das ações executadas pelos sistemas de saúde e de educação com vistas à atenção integral à saúde de crianças e adolescentes, onde todo profissional de saúde que atua na atenção básica e pratica o PSE emprega a comunicação humanizada direcionada para o indivíduo e a família, cria vínculo efetivo com a família e a escola, executa a orientação preventiva, participa do planejamento e execução do processo de avaliação de saúde nas escolas, identifica casos de maior risco à saúde, realiza consulta clínica e faz agendamentos ambulatoriais e em domicílios. ${ }^{6}$

O PSE no município apresenta fragilidades apesar da importância reconhecida. Houve contradição entre as falas dos enfermeiros e dos escolares com relação às práticas e ao funcionamento do programa, ficando evidente a necessidade de integração e a articulação intersetorial, além de fornecer um conjunto de atividades capazes de estimular e enriquecer o trabalho educativo dos profissionais envolvidos.

Apesar da literatura mostrar que a ação intersetorial e parceria entre as categorias de profissionais envolvidas na promoção da saúde na escola funcionam melhor quando todos trabalham para atingir um objetivo comum, ${ }^{5}$ o educador físico não foi citado neste estudo, porque, até o momento desta pesquisa, eles não estavam inseridos nas atividades práticas do PSE deste município.

\section{Limitações do estudo}

Uma das limitações deste estudo foi o período do ano letivo em que os questionários foram aplicados. Provavelmente, algumas das ações ainda não haviam sido realizadas pelos enfermeiros com alguns escolares das turmas do $6^{\circ}$ ano do ensino fundamental, bastante numerosas. Por outro lado, a principal razão para a escolha destes escolares foi a vivência das ações do PSE no ciclo I do fundamental, garantida pelo fato de que as escolas selecionadas estavam sob supervisão de um mesmo enfermeiro, na área de atuação da ESF. Pelo tempo de serviço dos profissionais participantes, o vínculo com o ambiente escolar já estava estabelecido e os resultados são, portanto, representativos para a prática desse programa nas escolas avaliadas.

\section{CONCLUSÃO}

Embora os alunos percebam a importância do enfermeiro na melhoria de sua qualidade de vida, muitas ações desenvolvidas por este profissional não foram identificadas pela maioria dos alunos, na maioria das escolas avaliadas. O excesso de atribuições na ESF, a ausência de envolvimento das escolas, a falta de articulação entre as secretarias de saúde e educação, a falta de engajamento de outros profissionais nas atividades desenvolvidas constitui limitações ao sucesso do programa PSE, segundo os enfermeiros.

\section{Conflitos de interesse}

Os autores declaram não haver conflitos de interesse.

\section{Contribuição dos autores}

Katrine Nascimento de Carvalho - concepção e delineamento do estudo; aquisição dos dados; redação preliminar.

Luciane Zanin - concepção e delineamento do estudo; análise e interpretação dos dados; revisão crítica da versão preliminar. 
Flávia Martão Flório - concepção e delineamento do estudo; análise e interpretação dos dados; revisão crítica da versão preliminar; orientação da mestranda.

\section{REFERÊNCIAS}

1. Sperândio AM, Carvalho FFB, Nogueira J, Zancan L, Akerman M. 10 years of the National Health Promotion Policy: progress and challenges. Ciênc Saúde Coletiva. 2016 Jun;21(6):1681-2. DOI: https://doi.org/10.1590/1413-81232015216.10862016

2. Ferreira IR, Vosgerau DS, Moysés SJ, Moysés ST. Normative measures of the Health in the School Program: content analysis associated with ATLAS TI software. Ciênc Saúde Coletiva. 2012 Dez;17(12):3385-98. DOI: https://doi.org/10.1590/s1413-81232012001200023

3. Eberhardt TD, Reis LF. Programa Saúde na Escola - PSE: estruturado de acordo com os princípios do SUS?. Anais do 5 Seminário Nacional Estado e Políticas Sociais. As políticas sociais nas transições latinoamericanas no século XXI: tendências e desafios. Cascavel, Paraná; 9-12 out 2011. Cascavel (PR): Universidade Estadual do Oeste do Paraná (UNIOESTE); 2011. p. 1-14.

4. Cesário NCM, Costa RJV, Pereira JT. O enfermeiro no ambiente escolar: práticas educativas atuais e eficazes. Revista Tecer. 2014 Mai;7(12):38-47.

5. Ministério da Saúde (BR). Secretaria de Atenção à Saúde. Departamento de Atenção Básica. Saúde na escola. Cadernos de Atenção Básica, n. 24. Série B. Textos Básicos de Saúde. Brasília (DF): Ministério da Saúde; 2009.

6. Ministério da Educação (BR). Secretaria da Educação Básica. Diretoria de Currículos e Educação Integral. Manual da educação integral em jornada ampliada para obtenção de apoio financeiro por meio do programa dinheiro direto na escola-PDE/educação integral: no exercício de 2011. Brasília (DF): Ministério da Educação; 2011.

7. Carvalho FFB. A saúde vai à escola: a promoção da saúde em práticas pedagógicas. Physis. 2015 Out/Dez;25(4):1207-27. DOI: https:// doi.org/10.1590/S0103-73312015000400009

8. Pires LM, Queirós PS, Munari DB, Melo CF, Souza MM. A enfermagem no contexto da saúde do escolar: revisão integrativa da literatura. Rev Enfermagem UERJ. 2012 Dez;20(spe 1):668-75.

9. Costa GM, Figueredo RC, Ribeiro MS. A importância do enfermeiro junto ao PSE nas ações de educação em saúde em uma escola municipal de Gurupi - TO. Rev Científica ITPAC. 2013 Abr;6(2):1-12.

10. Costa GMC, Cavalcanti VM, Barbosa ML, Celino SDM, França ISX, Sousa FS. Promoção de saúde nas escolas na perspectiva de professores do Ensino Fundamental. Rev Eletr Enf. 2013 Jun;15(2):506-15. DOI: https://doi.org/10.5216/ree.v15i2.15769

11. Maciel ELN, Oliveira CB, Frechiani JM, Sales CMM, Brotto LDA, Araújo MD. Project Learning Health in School: the experience of positive impact on the quality of life and health determinants of members of a community school in Vitória, Espírito Santo State. Ciênc Saúde Coletiva. 2010 Mar;15(2):389-96. DOI: https://doi.org/10.1590/S1413-81232010000200014

12. Machado WD, Oliveira KMCP, Cunha CG, Araújo Júnior DG, Silvino RHS, Araújo MS. "Dias Programa Saúde na Escola”: um olhar sobre a avaliação dos componentes. Rev Sanare. 2016;15(1):62-8.

13. Ministério da Saúde. Ministério da Educação (BR). Caderno do Gestor do PSE. Brasília (DF): Ministério da Saúde/Ministério da Educação;2015.

14. Bardin L. Análise de conteúdo. Lisboa: Edições 70; 1977.

15. R Core Team. Foundation for Statistical Computing. A language and environment for statistical computing [Internet]. Vienna: $\mathrm{R}$ Core Team Foundation for Statistical Computing; 2015.

16. Silva KL, Sena RR, Gandra EC, Matos JAV, Coura KRA. Promoção da saúde no programa saúde na escola e a inserção da enfermagem. Rev Min Enferm. 2014 Jul/Set;18(3):614-22. DOI: https://doi.org/10.5935/1415-2762.20140045

17. Maia JA, Menezes FA, Santos PAM. Percepção dos pais sobre a importância de acompanhamento do crescimento e desenvolvimento infantil. DêCiência em Foco. 2017;1(2):53-63.

18. Sousa MC, Esperidião MA, Medina MG. Intersectorality in the 'Health in Schools' Program: an evaluation of the political-management process and working practices. Ciênc Saúde Coletiva. 2017 Jun;22(6):1781-90. DOI: https://doi.org/10.1590/1413-81232017226.24262016

19. Nickel DA, Lima FG, Silva BB. Modelos assistenciais em saúde bucal no Brasil. Cad Saúde Pública. 2008 Fev;24(2):241-6. DOI: https:// doi.org/10.1590/S0102-311X2008000200002

20. Belotti L, Martinelli KG, Garcia EM, Santos MLL, Pacheco KTS, Esposti CDD. Evolução da atenção em saúde bucal antes e após a política nacional de saúde bucal. Rev Bras Pesqui Saúde. 2019;21(3):30-8. 
21. Santiago LM, Rodrigues MT, Oliveira Junior AD, Moreira TM. School Health Program implementation in Fortaleza-CE: performance of the Family Health Strategy staff. Rev Bras Enferm. 2012 Nov/Dez;65(6):1026-9. DOI: https://doi.org/10.1590/s0034-71672012000600020

22. Faial LCM, Silva RMCRA, Pereira ER, Souza LMC, Bessa RT, Faial CSG. Saúde na escola: contribuições fenomenológicas a partir da percepção do aluno adolescente. Rev Enferm UFPE On Line. 2017;11(1):24-30.

23. Ministério da Saúde. Ministério da Educação (BR). Manual instrutivo: programa saúde na escola. Brasília (DF): Ministério da Saúde/ Ministério da Educação; 2013.

24. Medeiros ERD, Pinto ESG, Paiva ACS, Nascimento CPA, Rebouças DGC, Silva SYB. Facilidades e dificuldades na implantação do Programa Saúde na Escola em um município do nordeste do Brasil. Rev Cuid. 2018;9(2):2127-34. DOI: https://doi.org/10.15649/cuidarte.v9i2.514

25. Barreto MASC. Caracterizando e correlacionando dislexia do desenvolvimento e processamento auditivo. Rev Psicopedagogia. 2009;26(79):88-97.

26. Baggio MA, Berres R, Gregolin BPS, Aikes S. Introduction of the School Health Program in the city of Cascavel, Paraná State: report of nurses. Rev Bras Enferm. 2018;71(Supl 4):1540-7. DOI: https://doi.org/10.1590/0034-7167-2017-0188 